\title{
Association between serum inhibin-B levels and coronary artery disease in aging males
}

\author{
Hasan Kocoglü, Cabir Alan², Dilek Ulker Cakır ${ }^{3}$, Ercan Malkoc ${ }^{4}$, Kahraman Cosansu', \\ Bahadır Kırılmaz ${ }^{6}$, Yunus Ertung², Ahmet Resit Ersay²
}

1Department of Urology, Canakkale Military Hospital, Turkey
2Department of Urology, Medicine Faculty, Canakkale Onsekiz Mart University, Turkey
3Department of Biochemistry, Medicine Faculty, Çanakkale Onsekiz Mart University,
Turkey
4Department of Urology, Corlu Military Hospital, Turkey
5Department of Cardiology, Canakkale Military Hospital, Turkey
6Department of Cardiology, Medicine Faculty, Canakkale Onsekiz Mart University, Turkey

Submitted: 23 September 2011

Accepted: 12 July 2012

Arch Med Sci 2013; 9, 5: 796-801

DOI: $10.5114 /$ aoms.2013.34410

Copyright (C 2013 Termedia \& Banach

\begin{abstract}
Introduction: Atherosclerosis is a systemic disorder. It is a frequent leading cause of coronary artery disease (CAD). Similarly, atherosclerotic vascular alterations could lead to testicular arterial blood flow reduction and impairment of testicular function with age. Inhibin-B has been validated as a valuable serum marker of testicular functions and its correlation with testicular volume was shown in some studies done before. The purpose of this study is to investigate the association between serum inhibin-B levels and CAD in elderly men.

Material and methods: Between March 2009 and March 2010, fifty-two 50-80year-old consecutive patients with Gensini score over 20 and ejection fraction (EF) $>50 \%$ were included in the study as the CAD group. Fifty healthy men without any cardiac disease history were recruited as the control group. All patients in the CAD group who had indications for coronary artery angiography underwent selective coronary artery angiography.

Results: Inhibin-B, total testosterone and testicular volume levels were found to be significantly lower in the CAD group in comparison with the control group ( $p=0.004, p<0.0001$, and $p=0.001$ respectively).

Conclusions: In this study, although no correlation was found in CAD patients between Gensini score and inhibin-B or testicular volume, inhibin-B levels and testicular volume were significantly lower in patients with $C A D$ than in healthy men. In order to fully assess the relationship between serum inhibin-B levels and $C A D$, multi-centered prospective and longitudinal studies must be done in elderly male patients.
\end{abstract}

Key words: inhibin-B, coronary artery disease.

\section{Introduction}

Atherosclerosis is a systemic disease that affects the whole vascular system. It is the most common form of arteriosclerosis and is defined as the hardening of small arteries and arterioles. The most important disease caused by atherosclerosis is coronary artery disease. Coronary artery disease (CAD) is the end result of the accumulation of atheromatous plaques within the walls of the coronary arteries and it is the leading cause of death worldwide. In the U.S. 13 million people die from CAD every year [1].

\author{
Corresponding author: \\ Hasan Kocoglu \\ Department of Urology \\ Canakkale Military Hospital \\ Canakkale, Turkey \\ Phone: +9028621724601241 \\ E-mail: \\ perkutanci@yahoo.com
}


Several studies have shown that atherosclerosis is an important factor for the development of erectile dysfunction (ED) [2, 3]. Smaller penile arteries suffer from obstruction earlier than the larger coronary arteries, so ED can be symptomatic before a coronary event [4]. In addition, atherosclerotic vascular alterations could lead to testicular arterial blood flow reduction and impairment of spermatogenesis [5]. Systemic arteriosclerosis is involved in the decline of testicular function with age $[6,7]$. Testicular parenchymal fibrosis is associated with defective vascularization of the testicular parenchyma and with systemic arteriosclerosis of affected men. These findings were supported by arteriographic patterns of the epididymis and the testis which correlate with the degree of systemic arteriosclerosis [7]. It seems possible that the degree of pathological change in the testicular arteries can be negatively correlated with the degree of spermatogenetic reduction [5]. Also, agerelated moderate decrease in testicular volume reflects a decrease in Sertoli cellular mass [8].

Inhibin-B has been validated as a valuable serum marker of Sertoli cell function and spermatogenesis [9-11] and also its correlation with testicular volume has been reported [8]. In the light of information mentioned above, we developed a hypothesis that systemic atherosclerosis can lead to narrowing of testicular arteries before coronary arteries as in the penile arteries. Decreased testicular blood supply can lead to decrease in testicular volume and/or serum inhibin-B levels. According to our theory, atherosclerosis can cause CAD and decreased inhibin-B levels in elderly male patients, so we can say that there is a relation between inhibin-B and CAD.

There have been no studies done before about the association between inhibin-B and CAD. The purpose of this study is to investigate the relationship between serum inhibin-B levels and CAD in elderly males.

\section{Material and methods}

Between March 2009 and March 2010 we designed our study as two groups. In the first group we performed coronary angiography according to the treadmill test in the 52 consecutive male patients who had coronary symptoms and traditional risk factors for CAD including age, hypertension, dyslipidemia, smoking habit and family history and this group was named as the CAD group (age range: $50-80$ years). Patients with Gensini scores lower than 20 points after coronary angiography and ejection fraction $(\mathrm{EF})<50 \%$ after echocardiography were not included in the CAD group. In addition, 50 asymptomatic men who had no risk factors for CAD or indications for coronary angiography according to the treadmill test were recruited as the control group (range: 50-80 years). Exclu- sion criteria included the following: hepatic dysfunction, diabetes mellitus, malignancy, endocrine diseases, left ventricular dysfunction (left ventricular $\mathrm{EF}<50 \%)$, unstable angina pectoris and myocardial infarction, valvular heart disease and obesity (BMI > $30 \mathrm{~kg} / \mathrm{m}^{2}$ ).

In addition to the impracticality of obtaining semen samples from large numbers of elderly men, the use of semen analysis in epidemiological studies is hampered by technical problems $[12,13]$. For similar reasons, we used testicular volume and inhibin-B levels in assessing testicular function in our study. Fasting morning blood samples were taken from patients between 08.00 and $09.00 \mathrm{am}$ from an antecubital vein. Inhibin-B was analyzed by using ELISA (sandwich enzyme-linked immuno-sorbent assay, Uscn Life Science Inc., Wuhan, China). Total testosterone levels were measured by enzyme immunoassay with the Roche Diagnostic total testosterone kit (Cobas c 501, Roche Diagnostic, Hitachi, Japan). Follicle-stimulating hormone (FSH) and luteinizing hormone $(\mathrm{LH})$ were analyzed using chemiluminescence assays (Immulite 2000, USA). Fasting blood glucose, total cholesterol and highdensity lipoprotein (HDL) cholesterol were measured by different laboratory techniques. Measurement of low-density lipoprotein (LDL) cholesterol levels were calculated using the formula as described by Friedewald et al. [14].

Testicular dimensions were measured by using ultrasonography with a 7.5-MHz probe (GE logiq 5 pro) in accordance with the published criteria of Behre et al. [15]. The testicular volume was calculated using the following formula: $V=\pi / 6 \times L \times D^{2}$, where $V=$ testis volume, $L=$ maximal length of the testis, and $D=$ maximal diameter of the testis. The mean testicular volume was calculated as the sum of the right and left testis volumes divided by two. Exclusion criteria for this measurement and inhibin-B level included the following: cryptorchidism, testicular torsion, orchitis, unilateral severe atrophic testes, orchidopexy history and varicocele. Also patients with infertility, hypogonadism and chemotherapy or radiotherapy history were excluded.

\section{Cardiac catheterization and determination of the severity of coronary artery stenosis}

All patients in the CAD group who had indications for coronary artery angiography underwent selective coronary angiography. The Judkins system was applied for cannulation of the left and right coronary arteries following femoral artery cannulation. Stenotic lesions in all major epicardial coronary arteries including left main (LMCA), left anterior descending (LAD), circumflex (CX), and right coronary (RCA) arteries were assessed. The severity of coronary artery disease was classified according to the Gensini scoring system [16], which grades 
Table I. Comparison of two groups due to different parameters

\begin{tabular}{|c|c|c|c|}
\hline Parameter & Group & Mean \pm SD & Value of $p$ \\
\hline \multirow[t]{2}{*}{ Age [year] } & Control & $59.64 \pm 8.1$ & 0.72 \\
\hline & CAD & $61.44 \pm 7.5$ & \\
\hline \multirow[t]{2}{*}{ Inhibin-B [ng/l] } & Control & $152.4 \pm 19.83$ & 0.004 \\
\hline & CAD & $134.6 \pm 26.73$ & \\
\hline \multirow{2}{*}{$\begin{array}{l}\text { Testosterone } \\
{[\mathrm{ng} / \mathrm{ml}]}\end{array}$} & Control & $6.37 \pm 3.09$ & 0.0001 \\
\hline & CAD & $3.14 \pm 1.53$ & \\
\hline \multirow{2}{*}{$\begin{array}{l}\text { Testicular volume } \\
{[\mathrm{ml}]}\end{array}$} & Control & $23.42 \pm 9.1$ & 0.001 \\
\hline & CAD & $18.61 \pm 7.6$ & \\
\hline \multirow[t]{2}{*}{$\mathrm{FSH}[\mathrm{mlU} / \mathrm{ml}]$} & Control & $7.67 \pm 5.71$ & 0.24 \\
\hline & CAD & $6.26 \pm 6.04$ & \\
\hline \multirow[t]{2}{*}{$\mathrm{LH}[\mathrm{mlU} / \mathrm{ml}]$} & Control & $6.45 \pm 2.81$ & 0.98 \\
\hline & CAD & $6.43 \pm 8.36$ & \\
\hline \multirow[t]{2}{*}{$\mathrm{HDL}[\mathrm{mg} / \mathrm{dl}]$} & Control & $47.44 \pm 9.94$ & 0.89 \\
\hline & CAD & $47.11 \pm 14.82$ & \\
\hline \multirow[t]{2}{*}{ LDL [mg/dl] } & Control & $116.19 \pm 33.62$ & 0.29 \\
\hline & CAD & $123.92 \pm 37.08$ & \\
\hline \multirow{2}{*}{$\begin{array}{l}\text { Blood glucose } \\
{[\mathrm{mg} / \mathrm{dl}]}\end{array}$} & Control & $106.89 \pm 25.25$ & 0.018 \\
\hline & CAD & $121.10 \pm 30.43$ & \\
\hline \multirow[t]{2}{*}{ Gensini score } & Control & - & \\
\hline & CAD & $51.33 \pm 34.96$ & \\
\hline
\end{tabular}

narrowing of the lumens of the coronary arteries as 1 for $1-25 \%$ narrowing, 2 for $26-50 \%$ narrowing, 4 for $51-75 \%$ narrowing, 8 for $76-90 \%$ narrowing, 16 for $91-99 \%$ narrowing, and 32 for total occlusion. This score is then multiplied by a factor that evaluates the importance of the lesion's position in the coronary arterial tree with 5 for the left main coronary artery, 2.5 for the proximal LAD or proximal $C x, 1.5$ for the mid-region of the LAD, and 1 for the distal LAD or mid-distal region of the Cx. A Gensini

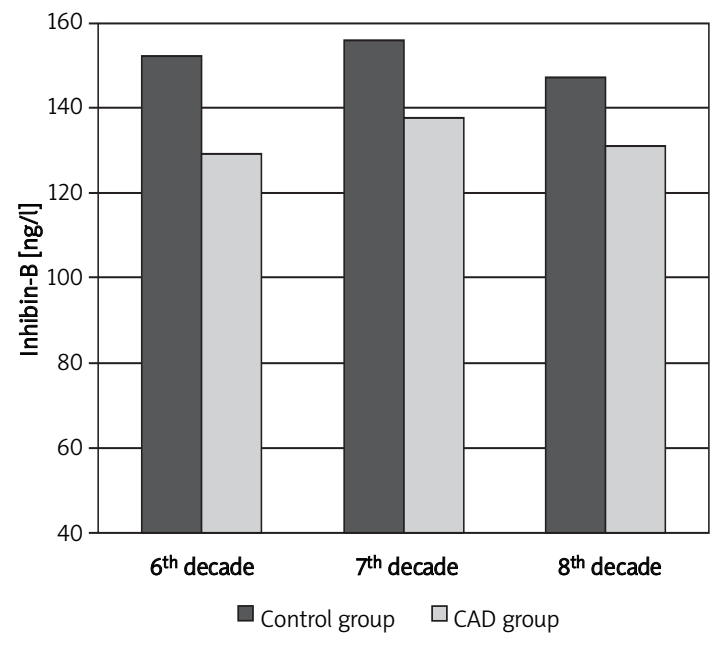

Figure 1. Inhibin-B levels in both groups score between 1 and 20 was considered mild whereas a score of $\geq 20$ was considered severe coronary atherosclerosis.

\section{Statistical analysis}

Values are expressed as mean \pm SD in the text unless otherwise stated. Differences between the groups were analyzed using the independent samples test for continuous variables and Mann-Whitney test for categorical variables. The Pearson correlation coefficient was calculated between variables using a 2-tailed significance test for variables. A value of $p<0.05$ was considered statistically significant. Data were analyzed using SPSS (Ver. 17.0, SPSS Inc., Chicago, IL).

\section{Results}

The findings of the CAD and control group are summarized in Table I. The mean ages in the CAD and control groups were $61.44 \pm 7.5$ and $59.64 \pm 8.1$ years, respectively. We found that inhibin-B, total testosterone and testicular volume were statistically significantly lower in the CAD group $(p=0.004$, $p<0.0001$, and $p=0.001$ respectively). Inhibin-B levels were lower in CAD groups for all three decades (see Figure 1). In addition, fasting blood sugar levels were found higher in the CAD group $(p=0.018)$.

The correlations between the variables studied within CAD groups are shown in Table II. Negative correlations were found between the Gensini score and HDL and between testosterone and fasting blood sugar levels in the CAD group $(r=-0.393$, $p=0.007, r=-0.228, p=0.029$ respectively), but no other correlations were found in the CAD group. Adjusting the analysis for age, testosterone, inhibin- $B$, and testicular volume did not modify this association.

\section{Discussion}

This is the first report to analyze the relationship between $C A D$, testicular volume and serum inhibin-B levels in elderly men in detail. To the best of our knowledge, we have shown for the first time that serum inhibin-B levels and testicular volume were significantly lower in patients with CAD who have preserved EF than in non-CAD cases. In order to study the impact of atherosclerosis on Sertoli cells in aging males, in whom we cannot perform testicular biopsy purely for research purposes, we measured the levels of inhibin-B in serum instead.

There are only a few studies that examine atherosclerosis and histological changes in the testes of aging men [5, 7, 17-19]. In these studies, data are obtained from autopsies and those studies suggested that microangiopathic degeneration is a characteristic finding for testicular senescence. 
Table II. Correlation analysis of age, Gensini score, T levels, inhibin-B level, testicular volume and other parameters in the CAD group

\begin{tabular}{|lcccccccccc|}
\hline \multirow{2}{*}{ Parameter } & \multicolumn{2}{c}{ Age } & \multicolumn{2}{c}{ Gensini score } & \multicolumn{2}{c}{ Inhibin-B } & \multicolumn{2}{c}{ Testosterone } & \multicolumn{2}{c|}{ Testicular volume } \\
\cline { 2 - 11 } & $r$ & $p$ & $r$ & $p$ & $r$ & $p$ & $r$ & $p$ & $r$ & $p$ \\
\hline Age & 1 & & 0.191 & 0.198 & 0.090 & 0.539 & 0.035 & 0.811 & -0.086 & 0.490 \\
\hline Gensini score & 0.191 & 0.198 & 1 & & 0.073 & 0.617 & -0.198 & 0.173 & 0.034 & 0.690 \\
\hline Inhibin-B & 0.090 & 0.539 & 0.073 & 0.617 & 1 & & 0.275 & 0.053 & 0.162 & 0.286 \\
\hline Testosterone & 0.035 & 0.811 & -0.198 & 0.173 & 0.275 & 0.053 & 1 & 0.092 & 0.520 \\
\hline $\begin{array}{l}\text { Testicular } \\
\text { volume }\end{array}$ & -0.086 & 0.490 & 0.034 & 0.690 & 0.162 & 0.286 & 0.092 & 0.520 & 1 & 0.120 \\
\hline FSH & -0.001 & 0.997 & -0.039 & 0.797 & -0.082 & 0.576 & -0.227 & 0.120 & 0.120 & 0.522 \\
\hline LH & 0.109 & 0.455 & -0.082 & 0.577 & 0.037 & 0.799 & -0.078 & 0.588 & 0.164 & 0.395 \\
\hline HDL & 0.087 & 0.562 & -0.393 & 0.007 & -0.152 & 0.303 & 0.026 & 0.863 & -0.192 & 0.246 \\
\hline LDL & 0.010 & 0.949 & 0.143 & 0.342 & 0.225 & 0.125 & 0.170 & 0.253 & 0.122 & 0.248 \\
\hline Blood glucose & 0.152 & 0.151 & 0.275 & 0.078 & -0.090 & 0.395 & -0.228 & 0.029 & -0.124 & 0.516 \\
\hline
\end{tabular}

Klein et al. [5] reported that atherosclerosis in the testicular vessels correlated only partly with the degree of general atherosclerosis. Contrary to the expectation, their findings showed that excessive pathological alterations of the testicular arteries were not correlated with testicular volume. However, normal spermatogenesis was found in a remarkable number of cases with excessive vessel alterations, evidently independent of the degree of stenosis. In our study, we found that testicular volume and inhibin-B levels, which are accepted as markers of testicular function, decreased in patients with severe CAD. The findings of a study done by Regadera [7] were similar to our study results. The study reported that testicular alterations in elderly men were correlated with the degree of aortic atherosclerosis. In addition, their results suggested that systemic arteriosclerosis leads to a decline in testicular function with age.

Decrease in testicular function with age has a complex mechanism. Significant reductions in levels of inhibin-B and inhibin-B/FSH ratio with age have been reported [20] before. When two groups were assessed separately in our study, no significant change in FSH and inhibin-B levels with age is found. Moreover, when the two groups were compared, no difference was found in FSH levels. On the other hand, inhibin-B levels were found to be significantly reduced in the CAD group. Age-related differences in the human testis include reductions in the volume or number of T-producing Leydig cells and changes in the morphology and number of Sertoli cells [21]. In the light of these findings, the mechanisms which are responsible for age-related decline in testicular function are intrinsic to the testis or they happen in addition to defects in the hypothalamic-pituitary-gonadal axis [22]. The results of our study tend to support the idea of deterioration in testicular function and it may have intrinsic causes rather than being caused by a decline in hormonal control mechanisms. According to our results, aging itself did not affect inhibin-B levels, yet inhibin-B levels were lower in patients who have CAD. Therefore, we suggested that atherosclerosis is a very important factor for deterioration of testicular function.

Global testicular Sertoli cell function and spermatogenesis activity in ambulatory elderly men, as assessed indirectly through serum inhibin-B levels, appear to be well maintained [23]. Similarly in our study, we found that inhibin-B levels were normal in the control group and there was no significant reduction with aging. Also no significant reduction in average testis volume with age was found.

There is a strong association between total testicular volume and serum inhibin-B levels reported in young men [13] and this is also true for the elderly [8]. Multivariate analyses show that in the elderly but not in young males, serum inhibin-B is associated with testicular volume independent from serum FSH levels. In our study both groups' FSH levels were similar, but inhibin-B levels were lower in the CAD group. This finding supports Mahmoud et al.'s statement that inhibin-B may be related to testis volume without regard to FSH.

There are a few detailed studies on spermatogenic function of the testis in aging men. A variety of reports have suggested that testicular volume decreases with age [24]. According to Paniagua et al., although the volume occupied by the seminiferous tubules decrease with age, the volume occupied by the testicular interstitium remains constant [25]. Since over $90 \%$ of testicular volume is occupied by the seminiferous tubules [26], spermatogenesis probably decreases in parallel with the decline in overall testicular size. According to Yang 
et al., testicular volume and metabolism remain relatively constant with only a minimal decrease between the ages of 40 and 60 years. After the age of 60 years, testicular volume decreases significantly, while testicular metabolism decreases progressively until the age of 90 years [6]. In our study, no significant reduction in testis volume with age was found. However, the average testicular volume of patients with CAD was significantly lower than the control group.

In our study there is no correlation between Gensini score and inhibin-B or testicular volume in $C A D$ patients, yet inhibin-B levels and testicular volume were lower in men with CAD than in healthy men. What we found interesting is that inhibin- $B$ levels and testicular volume do not change with age in either group. According to our findings, the association between inhibin-B and CAD is not clear. The issue of the importance of inhibin- $B$ in $C A D$ needs more studies [27].

Our study has some limitations. One might question whether in a cross-sectional study the sample is representative for the general population. Indeed, our study population was relatively small and we cannot exclude that the small sample size, even when based on power calculations, can explain the lack of significance for correlations of serum inhibin-B levels, testicular volume and Gensini scores. However, assessing the association between serum inhibin-B levels might be considered if hundreds of patients can be investigated in multi-centered, prospective, and longitudinal studies with the participation of men under the age of 50 years.

In conclusion, although no correlation was found between Gensini score and inhibin-B or testicular volume in CAD patients, inhibin-B levels and testicular volume were significantly lower in men who had CAD as well as preserved EF than in healthy men. Also in men who have CAD between the ages of 50 and 80 years, levels of inhibin-B and testis volume did not change with age. The fact that Gensini score, inhibin-B levels and testis volume do not change with age suggests that the testicular and cardiac effects of atherosclerosis occur and stabilize well before the age of 50 years. In order to fully assess the association between serum inhibin-B levels and CAD, multi-centered prospective and longitudinal studies must be carried out with the participation of men under the age of 50 years.

\section{References}

1. American Heart Association. Heart disease and stroke statistics 2009 update: a report from the American Heart Association Statistics Committee and Stroke Statistics Subcommittee. Circulation 2009; 119: e21-181.

2. Montorsi F, Briganti A, Salonia A, et al. Erectile dysfunction prevalence, time of onset and association with risk factors in 300 consecutive patients with acute chest pain and angiographically documented coronary artery disease. Eur Urol 2003; 44: 360-5.

3. Solomon H, Man JW, Wierzbicki AS, Jackson G. Relation of erectile dysfunction to angiographic artery disease. Am J Cardiol 2003; 91: 230-1.

4. Montorsi P, Montorsi F, Schulman C. Is erectile dysfunction the "tip of the iceberg" of a systemic vascular disorder? Eur Urol 2003; 44: 352-4.

5. Klein R, Pfitzer P. Flow cytometry of postmortem human testicular tissue in cases of atherosclerosis. Cytometry 1984; 5: 636-43.

6. Yang H, Chryssikos T, Houseni M, Alzeair S, Sansovini M, Iruvuri $\mathrm{S}$. The effects of aging on testicular volume and glucose metabolism: an investigation with ultrasonography and FDG-PET. Mol Imaging Biol 2011; 13: 391-8.

7. Regadera J, Nistal M, Paniagua R. Testis, epididymis, and spermatic cord in elderly men. Correlation of angiographic and histologic studies with systemic arteriosclerosis. Arch Pathol Lab Med 1985; 109: 663-7.

8. Mahmoud AM, Goemaere S, El-Garem Y, Van Pottelbergh I, Comhaire FH, Kaufma JM. Testicular volume in relation to hormonal indices of gonadal function in communitydwelling elderly men testicular. J Clin Endocrinol Metab 2003; 88: 179-84.

9. Globerman H, Shen-Orr Z, Karnieli E, Aloni Y, Charuzi I. Inhibin B in men with severe obesity and after weight reduction following gastroplasty. Endocr Res 2005; 31: 17-26.

10. Andersson AM, MuĖller J, Skakkebaek NE. Different roles of prepubertal and postpubertal germ cells and Sertoli cell in the regulation of serum inhibin B levels. J Clin Endocrinol Metabol 1998; 83: 4451-8.

11. Petersen PM, Andersson AM, Rrth M, Daugaard G, Skakkebaek NE. Undectactable inhibin B serum levels in men after testicular irradiation. J Clin Endocrinol Metabol 1999; 84: 213-5.

12. Mahmoud AM, Depoorter B, Piens N, Comhaire FH. The performance of 10 different methods for the estimation of sperm concentration. Fertil Steril 1997; 68: 340-5.

13. Mahmoud AM, Comhaire FH, Depuydt CE. The clinical and biologic significance of serum inhibins in subfertile men. Reprod Toxicol 1998; 12: 591-9.

14. Friedewald WT, Levy RI, Frederickson DS. Estimation of the concentration of low-density lipoprotein cholesterol in plasma, without use of the preparative ultracentrifuge. Clin Chem 1972; 18: 499-502.

15. Behre HM, Nashan D, Nieschlag E. Objective measurement of testicular volume by ultrasonography: evaluation of the technique and comparison with orchidometer estimates. Int J Androl 1989; 12: 395-403.

16. Gensini GG. A more meaningful scoring system for determining the severity of coronary heart disease. Am J Cardiol 1983; 51: 606

17. Sasano N, Ichigo S. Vascular patterns of the human testis with special reference to its senile changes. Tokohu J Exp Med 1969; 99: 269-76.

18. Suoranta $H$. Changes in the small blood vessels of the adult human testis in relation to age and some pathological conditions. Virchows Arch (Pathol Anat) 1971; 352: 165-81.

19. Handelsman DJ, Staraj S. Testicular size: the effects of aging, malnutrition, and illness. J Androl 1985; 6: 144-51.

20. Neaves WB, Johnson L, Porter JC, Parker CR, Petty CS. Leydig cell numbers, daily sperm production and gonadotropin levels in aging men. J Clin Endocrinol Metab 1984; 49: 269-75. 
21. Johnson L. Spermatogenesis and aging in the human. J Androl 1986; 7: 331-54.

22. Veldhuis JD, Urban RJ, Lizarralde G, Johnson ML, Iranmanesh A. Attenuation of luteinizing hormone secretory burst amplitude as a proximate basis for the hypoandrogenism of healthy aging in men. J Clin Endocrinol Metab 1992; 75: 707-13.

23. Mahmoud AM, Goemaere S, De Bacquer D, Comhaire FH, Kaufman JM. Serum inhibin B levels in communitydwelling elderly men. Clin Endocrinol (Oxf) 2000; 53: 141-7.

24. Swerdloff RS, Heber D. Effects of aging on male reproductive function. In: Endocrine aspects of aging. Korenman SC (ed.). Elsevier Biomedical, New York 1982; 119-35.

25. Paniagua R, Nistal M, Saez FJ, Fraile B. Ultrastructure of the aging human testis. J Electron Microsc Technol 1991; 19: 241-60.

26. Kaler LW, Neaves WB. Attrition of the human Leydig cell population with advancing age. Anat Rec 1978; 192: 513-8.

27. Kaminski KA, Kozieradzka A, Bonda T, et al. Percutaneous coronary interventions affect concentrations of interleukin 6 and its soluble receptors in coronary sinus blood in patients with stable angina. Angiology 2009; 60: 322-8. 